\title{
An Optimization Study on the Pyrolysis of Polystyrene in a Batch Reactor
}

\author{
Hyun-Seob Song and Jae Chun Hyun \\ Department of Chemical Engineering, Korea University, Seoul 136-701, Korea \\ (Received 24 October $1998 \cdot$ accepted 2 April 1999)
}

\begin{abstract}
The pyrolysis process of polystyrene (PS) has been investigated to find optimal temperature profiles which minimize the reaction time and the reaction energy required for a given conversion in a batch reactor. Assuming that the fragmentation of PS in pyrolysis is described by the mechanism of random and/or specific degradations, we used a continuous kinetic model for solving three moment equations to determine the transient change of molecular weight distributions (MWD) of the polymers. We then converted this independent-variable minimization problem using a coordinate transformation to a dependent-variable minimization problem that yields the optimal temperature profiles as its solution. The optimization results obtained in this study encompass the cases of different objective functions which cover minimum reaction time, minimum energy consumed, or any combination of these. It has turned out that maintaining the reaction temperature constant at an optimal level is the best solution in this optimization problem. An economic cost function also has been introduced as the third objective function to be minimized in addition to the reaction time and the reaction energy. This new function can serve as a convenient measure to judge the performance of the pyrolysis process minimizing the involved cost.
\end{abstract}

Key words : Batch Reactor, Cost Minimization, Coordinate Transformation, Objective Functions, Optimization, Polymer Pyrolysis, Polystyrene (PS)

\section{INTRODUCTION}

Technological advances made in the plastics industry over the past several decades have steadily increased the volume of plastics used in various applications in human civilization. The abundance of these plastic goods, on the other hand, has continuously created plastic waste problems around the world. At the moment, most of these plastic wastes are disposed of through dumping into landfills or burning in incinerators along with other solid wastes. These conventional methods will, however, be phased out in the near future due to the serious environmental problems they entail. The lack of landfill space for dumping nonbiodegradable plastics, and toxic gases generated during the simple burning are the partial list of the obvious difficulties inherent in the currently employed wastes management methodology.

Meanwhile, the thermal recycling of waste plastics by means of pyrolysis has become the subject of significant industrial and academic interest in recent years as a promising alternative disposal option [Kaminsky, 1992]. The reason is two-fold : first, pyrolysis does not require dumping landfills and second, few toxic gases are generated because pyrolysis is carried out in the absence of oxygen. Developing environment-friendly and cost-effective pyrolysis processes is thus now an engineering challenge that is worth pursuing through process optimization techniques.

In this study, polystyrene (PS) has been chosen as an example material due to its wide occurrence in municipal solid wastes. It is known that high viscosity and low heat transfer

To whom correspondence should be addressed.

E-mail : jchyun@grtrkr.korea.ac.kr rate of the PS melts together with the complicated dependency of its reaction rates on the reactor geometry and mixing, pose problems for the commercial practices of PS melt recycling. To avoid these problems, degradation of PS in solution (e.g., mineral oil) has been proposed [Madras et al., 1997b], and we study that subject here.

Although there have been many published results on the kinetic mechanisms of polymer degradation [Westerhout et al., 1997], systematic optimization studies, based on mathematical models, of the degradation of polymers have not yet appeared in the literature. In the past only a simple power law model has been used to describe the pyrolysis kinetics of polymers [Westerhout et al., 1997; Flynn and Florin, 1985]. The discrepancies in the values of the kinetic constants are an example of the unavoidable consequences of using this power law model to describe the polymer degradation mechanism, since the evaporation and the chemical reactions occurring in the degradation are not distinguished in this model.

Recently, more advanced models for pyrolysis processes have been developed, i.e., random chain scission (RCD) model [Westerhout et al., 1997], and a continuous kinetics model by McCoy and his coworkers [1995, 1997, 1998]. The latter can track the evolution of both the reactants and products in terms of the molecular weight distributions (MWD) while the former exhibits the spectrum of products only.

We have conducted an optimization study on the PS pyrolysis in solution in a batch reactor employing the reaction temperature as a manipulated variable in the continuous population balance equations of the system. The objective functions of this optimization can be made from various system goals such as maximum yield, minimum reaction time, and minimum energy 
consumed. Obviously, depending upon the particular objective functions we have chosen, the optimization results could become different. To consider simultaneously the two most important objective functions of this study, i.e., minimum reaction time and minimum energy consumed for a given conversion, we have introduced an economic criterion: a single measure reflecting the economic values of the various PS products recovered during the pyrolysis.

\section{THEORETICAL MODELING}

\section{Degradation Mechanisms}

The thermal degradation of PS in solution in a batch reactor is generally carried out under a high pressure in a liquid phase in order to prevent vaporization of light components like solvent and monomers. The degradation of polymer molecules has been assumed to be represented by the two mechanisms of random and specific degradations. The former means the binary scission of polymer bonds at any position along the chain, whereas the latter the release of monomeric species (styrene in this case) by scission at the chain end [Wang et al., 1995]. Besides styrene monomers, dimers, trimers, etc. can also be handled in the model, but for the simplicity of the optimization methodology in this study only monomers are considered in the modeling of PS degradation as recovered products.

The random and specific degradations are described below.

$$
\begin{aligned}
& \text { Random degradation : } \mathrm{x}^{\prime} \stackrel{\mathrm{k}_{r}}{\longrightarrow} \mathrm{X}+\left(\mathrm{X}^{\prime}-\mathrm{x}\right) \\
& \text { Specific degradation : } \mathrm{X}^{\prime} \stackrel{\mathrm{k}_{s}}{\longrightarrow} \mathrm{X}_{s}+\left(\mathrm{X}^{\prime}-\mathrm{X}_{s}\right)
\end{aligned}
$$

where $\mathrm{x}^{\prime}$ and $\mathrm{x}$ denote molecular weights of polymers whereas $\mathrm{X}_{s}$ that of monomers, and $\mathrm{k}_{r}$ and $\mathrm{k}_{s}$ represent reaction rate constants of the random and specific degradations, respectively, shown below.

$$
\begin{aligned}
& \mathrm{k}_{r}=\mathrm{k}_{r 0} \exp \left(-\frac{\mathrm{E}_{r}}{\mathrm{RT}}\right) \\
& \mathrm{k}_{s}=\mathrm{k}_{s 0} \exp \left(-\frac{\mathrm{E}_{s}}{\mathrm{RT}}\right)
\end{aligned}
$$

Random degradation causes the main chains to break down randomly, which results in more smooth molecular weight distributions, while specific degradation (chain-end scission) is responsible for the formation of styrene monomers.

\section{Continuous Population Balance Equations}

Continuous kinetic models in which the molecular weight of the polymers is treated as a continuous variable have been successfully used to study polymer degradation problems in recent years [McCoy and Madras, 1997; Madras et al., 1997a, b; Wang et al., 1995]. Two assumptions are commonly incorporated : firstorder irreversible degradation reactions and equal reactivity for all degradation reactions irrespective of the chain length of polymer molecules involved in the reactions. The resulting rate equations for polymer degradation and monomer formation are as follows.

$$
\begin{aligned}
& \frac{\mathrm{df}(\mathrm{x}, \mathrm{t})}{\mathrm{dt}}=2 \mathrm{k}_{r} \int_{x}^{\infty} \Omega_{r}\left(\mathrm{x}, \mathrm{x}^{\prime}\right) \mathrm{f}\left(\mathrm{x}^{\prime}, \mathrm{t}\right) \mathrm{dx}^{\prime}-\mathrm{k}_{r} \mathrm{f}(\mathrm{x}, \mathrm{t}) \\
& +\mathrm{k}_{s} \int_{x}^{\infty} \Omega_{s}\left(\mathrm{x}^{\prime}-\mathrm{X}_{s}, \mathrm{X}^{\prime}\right) \mathrm{f}\left(\mathrm{x}^{\prime}, \mathrm{t}\right) \mathrm{dx^{ \prime } - \mathrm { k } _ { s }} \mathrm{f}(\mathrm{x}, \mathrm{t}) \\
& \frac{\mathrm{dg}(\mathrm{x}, \mathrm{t})}{\mathrm{dt}}=\mathrm{k}_{s} \int_{x}^{\infty} \Omega_{s}\left(\mathrm{x}_{s}, \mathrm{x}^{\prime}\right) \mathrm{f}\left(\mathrm{x}^{\prime}, \mathrm{t}\right) \mathrm{dx}^{\prime}
\end{aligned}
$$

where $f(x, t)$ and $g(x, t)$ are the MWDs of the polymers and the specific products, respectively. The stoichiometric kernels $\Omega_{r}$ ( $\left.\mathrm{x}, \mathrm{x}^{\prime}\right)$ and $\Omega_{s}\left(\mathrm{x}^{\prime}-\mathrm{x}_{s}, \mathrm{x}^{\prime}\right)$ in Eq. (5) are the probability density functions (PDF) for the polymers having the MW of $\mathrm{x}^{\prime}$ which are degraded to lower MW of $\mathrm{x}$ through random and specific fragmentation processes described in Eqs. (1) and (2), respectively. $\Omega_{s}\left(\mathrm{x}_{s}, \mathrm{x}^{\prime}\right)$ in Eq. (6) is the PDF for the monomers having the MW of $\mathrm{x}_{s}$ which are to be formed from polymer having the MW of $x^{\prime}$ through specific degradation of Eq. (2).

The first term on the right hand side of Eq. (5) accounts for the rate of generation of polymers having the MW of $\mathrm{x}$ by random scission path, while the second term the rate of disappearance of polymers by the same random path of Eq. (1). The third and fourth terms explain the same generation and disappearance processes of polymers, respectively, but this time by the specific degradation path of Eq. (2). Similarly, the right hand side of Eq. (6) refers to the rate of formation of monomers by specific degradation of Eq. (2).

The functional forms of the stoichiometric kernels for the random and specific degradations are given as follows [McCoy and Madras, 1997].

$$
\begin{aligned}
& \Omega_{r}\left(\mathrm{x}, \mathrm{x}^{\prime}\right)=1 / \mathrm{x}^{\prime} \\
& \Omega_{s}\left(\mathrm{x}^{\prime}-\mathrm{X}_{s}, \mathrm{x}^{\prime}\right)=\delta\left[\mathrm{x}-\left(\mathrm{x}^{\prime}-\mathrm{X}_{s}\right)\right] \\
& \Omega_{s}\left(\mathrm{x}_{s}, \mathrm{x}^{\prime}\right)=\delta\left(\mathrm{x}-\mathrm{X}_{s}\right)
\end{aligned}
$$

where $\delta$ is the Dirac delta function.

\section{Moment Equations}

We formulate moment equations by multiplying $\mathrm{x}^{n}$ to Eqs. (5) and (6) followed by integrating from zero to infinity:

$$
\int_{0}^{\infty} x^{n}[\text { Eqs. (5) and (6)] } d x
$$

The resulting equations for nth moments of the polymers and monomers, i.e., $\mathrm{f}^{(n)}(\mathrm{x}, \mathrm{t})$ and $\mathrm{g}^{(n)}(\mathrm{x}, \mathrm{t})$, are obtained as below (For the detailed derivation, see the Appendix.).

$$
\begin{aligned}
& \frac{d f^{(0)}(t)}{d t}=k_{r} f^{(0)}(t)=F_{1} \\
& \frac{d f^{(1)}(t)}{d t}=-k_{s} x_{s} f^{(0)}(t)=F_{2} \\
& \frac{d f^{(2)}(t)}{d t}=-(1 / 3) k_{r} f^{(2)}(t)-2 k_{s} x_{s} f^{(1)}(t)+k_{s} x_{s}^{2} f^{(0)}(t)=F_{3} \\
& \frac{d g^{(0)}(t)}{d t}=k_{s} f^{(0)}(t)=F_{4} \\
& \frac{d g^{(1)}(t)}{d t}=k_{s} x_{s} f^{(0)}(t)=F_{5}=x_{s} F_{4} \\
& \frac{d g^{(2)}(t)}{d t}=k_{s} x_{s}^{2} f^{(0)}(t)=F_{6}=x_{s}^{2} F_{4}
\end{aligned}
$$


where MW moments are defined as

$$
\begin{aligned}
& f^{(n)}(t)=\int_{0}^{\infty} x^{n} f(x, t) d x \\
& g^{(n)}(t)=\int_{0}^{\infty} x^{n} g(x, t) d x
\end{aligned}
$$

where the superscript $n$ indicates the order of the moments.

\section{Determination of MWD by a Gamma Distribution}

To represent the MWDs of the polymers and products, we employ a gamma distribution function. This function is known to be flexible enough to portray the MWDs of polymers very well. Other commonly used MWD functions such as exponential, Poisson, Gaussian, delta, and rectangular distributions are all special cases of this gamma distribution [Madras and McCoy, 1998]. Since the gamma distribution is completely determined by its first three moments, here we solve just the six moment equations of Eqs. (11) to (16) to track the evolution of MWDs instead of directly tackling Eqs. (5) and (6).

The molar fraction gamma distribution for polymers is then defined as

$$
\begin{aligned}
& f(x, t) / \int_{0}^{\infty} f(x, t) d x \\
& \quad= \begin{cases}\left(\frac{x-x_{0}}{\beta(t)}\right)^{\alpha(t)-1} \exp \left(-\frac{x-x_{0}}{\beta(t)}\right)[\beta(t) \Gamma(t)] & \text { for } x \geq x_{0} \\
0 & \text { for } x<x_{0}\end{cases}
\end{aligned}
$$

where $\mathrm{x}_{0}$ is the lowest MW in polymer samples, and the shape parameters of $\alpha(\mathrm{t})$ and $\beta(\mathrm{t})$ are given as below.

$$
\begin{aligned}
& \alpha(\mathrm{t})=\left[\overline{\mathrm{M}}_{n}(\mathrm{t})-\mathrm{x}_{0}\right] \beta(\mathrm{t})=\left[\overline{\mathrm{M}}_{n}(\mathrm{t})-\mathrm{x}_{0}\right]^{2} / \sigma^{2}(\mathrm{t}) \\
& \beta(\mathrm{t})=\sigma^{2}(\mathrm{t}) /\left[\overline{\mathrm{M}}_{n}(\mathrm{t})-\mathrm{x}_{0}\right]^{2}
\end{aligned}
$$

and

$$
\begin{aligned}
\bar{M}_{n}(t) & =\frac{\int_{0}^{\infty} x f(x, t) d x}{\int_{0}^{\infty} f(x, t) d x}=\frac{f^{(1)}(t)}{f^{(0)}(t)} \\
\sigma^{2}(t) & =\frac{\int_{0}^{\infty}\left[x-\bar{M}_{n}(t)\right]^{2} f(x, t) d x}{\int_{0}^{\infty} f(x, t) d x}=\frac{\int_{0}^{\infty} x^{2} f(x, t) d x}{\int_{0}^{\infty} f(x, t) d x}-\left[\bar{M}_{n}(t)\right]^{2} \\
& =\frac{f^{(2)}(t)}{\mathrm{f}^{(0)}(t)}-\left[\frac{\mathrm{f}^{(1)}(t)}{\mathrm{f}^{(0)}(\mathrm{t})}\right]
\end{aligned}
$$

The weight fraction gamma distribution for polymers is simply

$$
\mathrm{f}_{w}(\mathrm{x}, \mathrm{t})=\mathrm{xf}(\mathrm{x}, \mathrm{t})
$$

Fig. 1 shows the evolution of the MWD with time during the pyrolysis. The shift of the MWD toward the lower range of MW as reaction progresses is caused mainly by random degradation, and here the distinguished peak in the low MW region represents the styrene monomers formed by specific degradation (chain-end scission).

\section{FORMULATION OF THE OPTIMIZATION PROBLEM}

The principal issue in the pyrolysis study of plastic wastes is

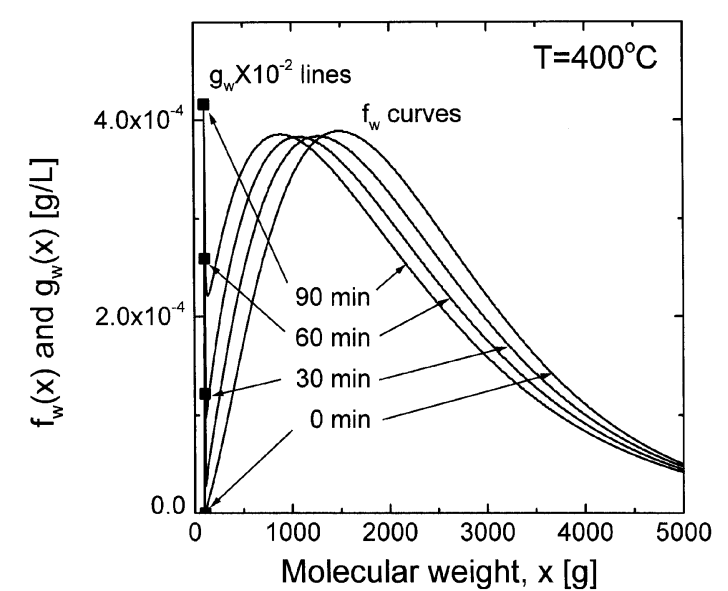

Fig. 1. Transient molecular weight distributions of the polymers and monomers during the pyrolysis.

to find the most environment-friendly and cost-effective pyrolysis technology, namely, a high monomer yield with both the reaction time and the consumed reaction energy being reduced as much as possible. In the study here, we set our optimization goal to be finding the optimal reactor temperature curves that simultaneously minimize the reaction time and the consumed energy for a given final conversion. So we have a nonlinear free-end-time/fixed-end-point problem. General standard solution methods for this kind of problem, however, have not been fully established yet.

To circumvent this problem, a coordinate transformation similar to those used by Kwon and Evans [1975] and Song et al. [1996] has been introduced to convert our problem to a fixedend-time/free-end-point type for which many standard solution methods have been known [Kirk, 1970]. This transformation is always possible when we can find at least one dependent variable that monotonically increases as the reaction proceeds. In most polymerization and depolymerization reactions, including the present polymer pyrolysis processes, the conversion of the reaction just satisfies this requirement. Hence by adopting this conversion as our new independent variable, we perform a coordinate transformation of the system.

First, the conversion in the pyrolysis processes is defined as

$$
\tau=1-\frac{\text { mass of polymers at time } t}{\text { initial mass of polymers }}=1-\frac{\mathrm{f}^{(1)}(\mathrm{t})}{\mathrm{f}_{0}^{(1)}}
$$

Differentiating both sides of this equation with respect to time, we get

$$
\frac{\mathrm{d} \tau}{\mathrm{dt}}=-\frac{1}{\mathrm{f}_{0}^{(1)}} \frac{\mathrm{df}^{(1)}(\mathrm{t})}{\mathrm{dt}}=\mathrm{F}^{*}
$$

Next, a coordinate transformation of the system equations is carried out by changing the variables as shown below.

$$
\begin{aligned}
& \mathrm{t} \rightarrow \mathrm{y}_{1} \\
& \mathrm{f}^{(0)} \rightarrow \mathrm{y}_{2} \\
& \mathrm{f}^{(2)} \rightarrow \mathrm{y}_{3} \\
& \mathrm{~g}^{(0)} \rightarrow \mathrm{y}_{4}
\end{aligned}
$$


The final state equations resulting from the above coordinate transformation are then as follows.

$$
\begin{aligned}
& \frac{d y_{1}}{d \tau}=\frac{1}{F^{*}}=G_{1} \\
& \frac{d y_{2}}{d \tau}=\frac{F_{1}}{F^{*}}=G_{2}, \frac{d y_{3}}{d \tau}=\frac{F_{3}}{F^{*}}=G_{3}, \text { and } \frac{d_{4}}{d \tau}=\frac{F_{4}}{F^{*}}=G_{4}
\end{aligned}
$$

The other dependent variables that are not transformed are simply rederived from the transformed variables (dependent and independent) as shown below.

$$
\begin{aligned}
& \mathrm{f}^{(1)}=\mathrm{f}_{0}^{(1)}(1-\tau) \\
& \mathrm{g}^{(1)}=\mathrm{x}_{s} \mathrm{y}_{4} \\
& \mathrm{~g}^{(2)}=\mathrm{x}_{s}^{2} \mathrm{y}_{4}
\end{aligned}
$$

Now the optimization problem becomes :

Find the temperature profile $(\mathrm{T}(\mathrm{t}))$ which minimizes

Objective function $\mathrm{J}=$ function of reaction time, reaction energy, or any combination of reaction criteria

subject to

$$
\begin{aligned}
& 310^{\circ} \mathrm{C} \leq \mathrm{T} \leq 500{ }^{\circ} \mathrm{C} \\
& \tau_{f}=0.9
\end{aligned}
$$

The temperature, the parameter which enters the system equations through the reaction rate constants of Eqs. (3) and (4), becomes the manipulating variable whose time dependence is the solution of this optimization problem. The temperature bounds of (37) have been chosen to ensure two things : the lower temperature is necessary to ensure degradation reactions, not the polymerization reactions, to take place [Odian, 1991], and the upper temperature is necessary to avoid products in undesirable states such as in the coking state [Van Krevelen, 1990]. The final conversion in the study was set at $90 \%$. The above optimization in general constitutes an unconstrained nonlinear optimization problem for which many nonlinear programming techniques like Davidson-Fletcher-Powell (DFP) or BroydenFletcher-Goldfarb-Shanno (BFGS) methods are available [Rao, 1996; Reklaitis et al., 1983].

Whereas the final reaction time is easily computed by solving the ordinary differential equations given by Eq. (31), the final total energy consumed is not readily obtained. So we have used here the following energy balance of the system for obtaining the total energy consumed.

$$
\rho \mathrm{c}_{p} \frac{\mathrm{dT}}{\mathrm{dt}}=\dot{\mathrm{q}}_{h}-\dot{\mathrm{q}}_{\mathrm{c}}+\left(-\Delta \mathrm{H}_{d}\right) \mathrm{r}_{d}
$$

where

$$
\begin{aligned}
& \dot{\mathrm{q}}_{c}=\mathrm{U}(\mathrm{A} / \mathrm{V})\left(\mathrm{T}-\mathrm{T}_{a}\right) \\
& \mathrm{r}_{d}=\frac{\mathrm{dc}_{s}}{\mathrm{dt}}=\frac{\mathrm{dg}^{(0)}}{\mathrm{dt}}=\mathrm{k}_{s} \mathrm{f}^{(0)}(\mathrm{t})
\end{aligned}
$$

Here $\Delta \mathrm{H}_{d}$ in Eq. (39) is defined as the heat of depolymerization per unit mole of monomer which is produced by Eq. (41) through the specific degradation reaction only.

Then the total energy consumption during the pyrolysis can be divided into three parts as shown below.

$$
\begin{aligned}
\mathrm{J} & =\int_{0}^{t_{t}}\left(\mathrm{~V} \dot{\mathrm{q}}_{h}\right) \mathrm{dt} \\
& =\mathrm{V} \int_{0}^{t_{f}}\left[\rho \mathrm{c}_{p} \frac{\mathrm{dT}}{\mathrm{dt}}+\dot{\mathrm{q}}_{c}+\left(\Delta \mathrm{H}_{d}\right) \mathrm{r}_{d}\right] \mathrm{dt} \\
& =\underbrace{\left.\mathrm{mc}_{p}\right]_{0}^{t_{j}} \frac{\mathrm{dT}}{\mathrm{dt}} \mathrm{dt}}_{=\mathrm{E}_{1}}+\underbrace{\mathrm{UA} \int_{0}^{t_{f}}\left(\mathrm{~T}-\mathrm{T}_{a}\right) \mathrm{dt}}_{=\mathrm{E}_{2}}+\underbrace{\mathrm{V}\left(\Delta \mathrm{H}_{d}\right) \int_{0}^{t_{t}} \frac{\mathrm{dg}^{(0)}}{\mathrm{dt}} \mathrm{dt}}_{=\mathrm{E}_{3}}
\end{aligned}
$$

The first term is for elevating the reaction from room temperature to the operating temperature, the second term for compensating the heat loss and the third term for providing heat to the endothermic pyrolysis reactions.

\section{RESULTS AND DISCUSSION}

The results of the above optimization problem are shown in Table 1. Case I represents the results when the objective function is the reaction time and the constraints are none. Actually this is a trivial result because the reaction time is minimal when the highest possible temperature is followed in the reaction, i.e., $500^{\circ} \mathrm{C}$ in this case. As a matter of fact, as shown in Fig. 2, the reaction time becomes shorter as the constant reaction temperature gets higher. In other words, in Case I, in order to attain the minimum reaction time we have to pay a penalty on the reaction temperature, i.e., it stays on the maximum allowable level. It should be noted that since we have not imposed any constraints on the increasing rate of reactor temperature in this numerical study, the obtained optimal temperature trajectories take the shape in which the highest allowed temperature is instantly reached from the room temperature and is maintained thereafter on this constant level. If, however, a finite heating rate of the process is included as a constraint in the optimization problem, the optimal temperature trajectories will

Table 1. Optimization results when the objective function is the reaction time and/or the process energy

\begin{tabular}{ccccccccc}
\hline \hline Case & Objectives & Constraints & $\mathrm{T}\left[{ }^{\circ} \mathrm{C}\right]$ & $\mathrm{t}_{f}[\mathrm{hr}]$ & $\mathrm{E}_{T}[\mathrm{~kJ}]$ & $\mathrm{E}_{1}[\mathrm{~kJ}]$ & $\mathrm{E}_{2}[\mathrm{~kJ}]$ & $\mathrm{E}_{3}[\mathrm{~kJ}]$ \\
\hline I & Min. $\mathrm{t}_{f}$ & No & 500.0 & 0.23 & 167.2 & 104.8 & 0.42 & 61.98 \\
II & Min. $\mathrm{E}_{T}$ & No & 420.7 & 4.50 & 153.0 & 84.1 & 6.97 & 61.98 \\
III & Min. $\mathrm{E}_{T}$ & $\mathrm{t}_{f} \leq 2.0$ & 441.9 & 2.00 & 154.7 & 89.5 & 3.23 & 61.98 \\
IV & Min. $\mathrm{E}_{T}$ & $\mathrm{t}_{f} \leq 1.5$ & 449.3 & 1.50 & 155.9 & 91.4 & 2.46 & 61.98 \\
V & Min. $\mathrm{E}_{T}$ & $\mathrm{t}_{f} \leq 1.0$ & 459.9 & 1.00 & 157.8 & 94.2 & 1.68 & 61.98 \\
VI & Min. $\mathrm{E}_{T}$ & $\mathrm{t}_{f} \leq 0.5$ & 478.4 & 0.50 & 161.9 & 99.0 & 0.88 & 61.98 \\
\hline
\end{tabular}




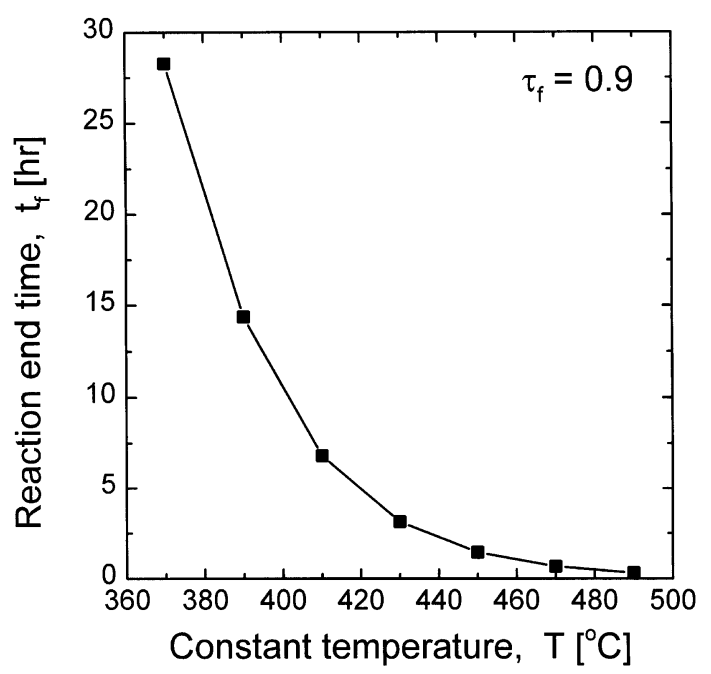

Fig. 2. Elapsed reaction time of the pyrolysis process.

take the shape of increasing curves.

Cases II to VI display the optimization results when the objective function is the reaction energy. As shown in Table 1, all the resulting optimal temperature trajectories are those of some constant levels. These interesting results can be explained by analyzing the three different individual energy terms of the total reaction energy as defined in Eq. (42).

First, according to the definition of $\mathrm{E}_{1}$, the energy for elevating the reaction temperature to the operating level depends on the initial and final temperatures only, not on the transient path. Furthermore, since we have assumed that the energy is required into the system only when the temperature increases with time (i.e., dT/dt $>0$ ), not when the temperature decreases (i.e., $\mathrm{dT} / \mathrm{dt}<0$ ), any fluctuating temperature profiles are excluded for the minimization of $\mathrm{E}_{1}$. For the case of $\mathrm{E}_{2}$, since the final time $\mathrm{t}_{f}$ is an exponentially decreasing function of temperature while the integrand $\left(\mathrm{T}-\mathrm{T}_{a}\right)$ linearly increases with temperature, which thus makes $\mathrm{E}_{2}$ a decreasing function of temperature, it is desirable for the minimum of $E_{2}$ to keep the temperature highest possible. Finally, $E_{3}$ depends on the final conversion only, and thus it becomes a constant value if the final conversion is fixed. Summing up these three cases for minimizing $E_{1}, E_{2}$ and $E_{3}$ in Eq. (42), we can find that overall optimum temperature trajectories for the minimum reaction energy $\mathrm{E}_{T}$ are constant temperature levels.

Now that we have explained why the constant temperature profiles have been obtained as the optimal temperature trajectories for all six cases of Table 1, we continue to conduct more of the detailed analysis of individual cases.

Case II represents the results when the objective function is the reaction energy with no constraints on the reaction time. There is the optimal constant reaction temperature in this case, i.e., $420.7^{\circ} \mathrm{C}$, which results in the minimum level of reaction energy. Here the penalty we have to pay is the longest reaction time of $4.5 \mathrm{hr}$.

Cases III, IV, V, and VI represent the results when the reaction energy is minimized with constraints on the reaction time. Since in real waste polymer pyrolysis processes we cannot allow

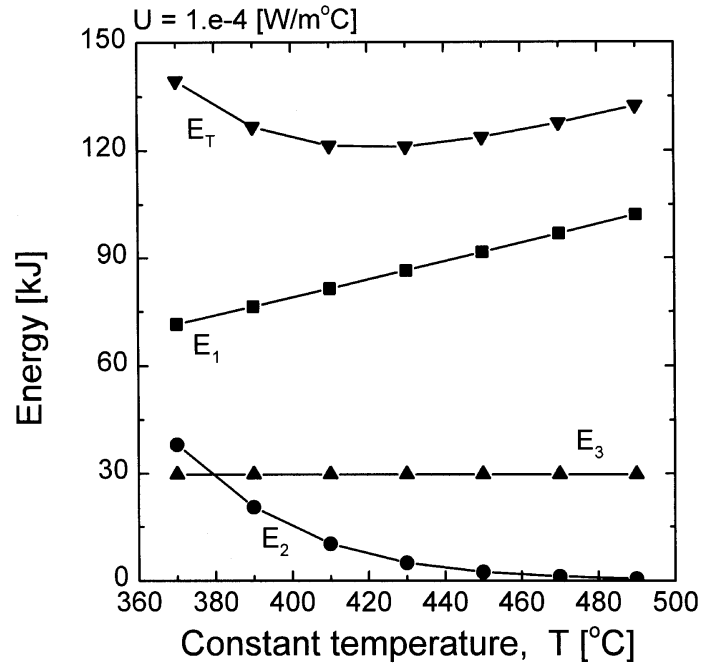

Fig. 3. Required energy for the cases of non-adiabatic pyrolysis process.

the reaction time to get too long, these cases are of practical importance. As the allowed reaction time becomes smaller, the optimal reaction temperature gets higher, which means that we have to pay progressively higher penalties

All the results in Table 1 were obtained when the reactor was not adiabatic. In other words, some heat transfer between the reactor and the environment occurred, namely, a non-zero heat transfer coefficient, $\mathrm{U}=1.0 \mathrm{E}-04 \mathrm{~W} / \mathrm{m}{ }^{\circ} \mathrm{C}$. If the pyrolysis is done in complete insulation, i.e., $\mathrm{U}=0$, the results are like those in Fig. 4. In other words, in this unrealistic adiabatic case, the trivial results are obtained, i.e., the lowest allowable reaction temperature is the solution giving the minimum reaction energy required. This is not a surprising result because the heat transfer term $\left(\mathrm{E}_{2}\right)$ in Eq. (42) which is a decreasing function of temperature makes the optimal solution possible in nonadiabatic cases in Table 1, while the other two terms in Eq. (42) are non-decreasing functions of temperature. So if the sec-

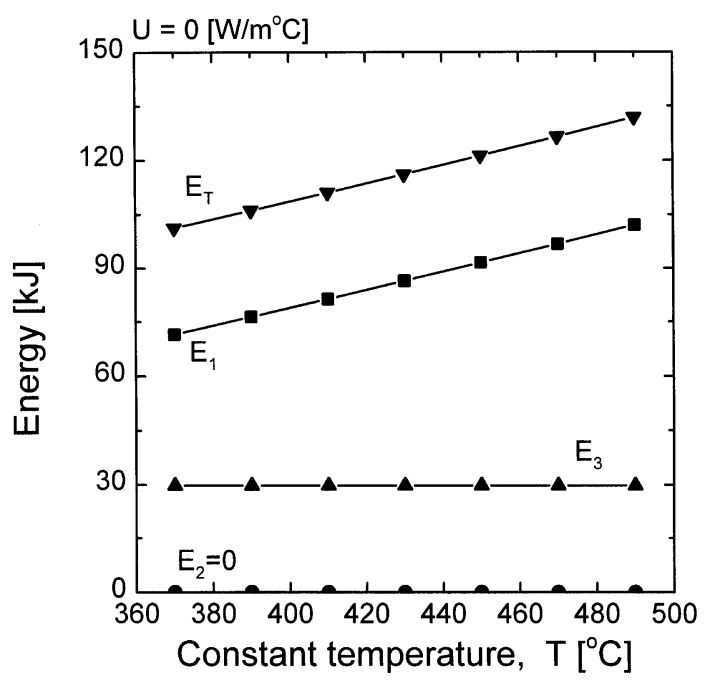

Fig. 4. Required energy for the cases of adiabatic pyrolysis process. 
ond term is set to zero, Eq. (42) becomes a monotonically increasing function of temperature.

As shown in Cases III to VI in Table 1 where minimum time and minimum energy are both sought after, in real pyrolysis processes some combinations of the optimization criteria are desirable to recommend the optimal pyrolysis strategy in realistic terms. As a reasonable candidate for the optimization criterion, we here introduce an economic cost objective function for the optimization problem as defined below.

$$
\begin{aligned}
\mathrm{C}_{T} & =\mathrm{E}_{T}^{*} \times\left(\begin{array}{c}
\text { utility } \\
\text { rate }
\end{array}\right)+\left(\frac{\mathrm{t}_{f}-\mathrm{t}_{f}^{*}}{\mathrm{t}_{f}^{*}}\right) \times\left(\begin{array}{c}
\text { monomer } \\
\text { production } \\
\text { profit }
\end{array}\right) \\
& =\mathrm{C}_{E}+\mathrm{C}_{M}
\end{aligned}
$$

where $E_{T}^{*}$ is the energy consumed for producing $1 \mathrm{~kg}$ of styrene monomer, $\mathrm{t}_{f}^{*}$ is the shortest realizable reaction time $(0.23$ $\mathrm{hr}$ in Case I of Table 1), and the utility rate means electricity cost per $1 \mathrm{~kJ}$ energy. Thus the first term of Eq. (43), $\mathrm{C}_{E}$, means the electricity cost and the second term, $\mathrm{C}_{M}$, refers to the unrealized monomer cost due to extra running time of the reactor beyond the shortest possible reaction time.

Now the above economic cost is used as an objective function to be minimized for the optimization problem. The same methods as used for the problems of minimum reaction time and/or minimum energy can be applied to obtain the optimum temperature profiles minimizing the cost function as defined by Eq. (43). One thing we have to consider here is the price of the recovered monomers as compared to the operating electricity cost because the optimization results will obviously depend on the relative ratio of these two terms in Eq. (43). Fig. 5 illustrates such results. When the price of recovered monomer price is high with relatively cheap electricity, our strategy for pyrolysis is to produce maximum amounts of monomer at high reaction temperature, similar to Case I of Table 1. On the other hand, when the price of recovered monomer is low with relatively expensive electricity, our strategy would be to run the reaction at low temperature, similar to Case II of Table 1.

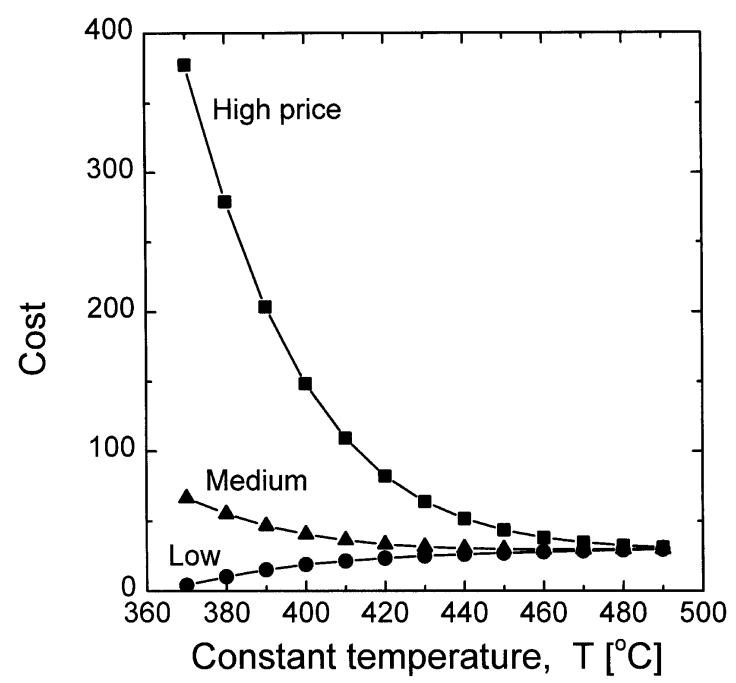

Fig. 5. Cost of the pyrolysis process with different price levels of recovered monomers.
Table 2. Optimization results when the objective function is the cost of the pyrolysis process

\begin{tabular}{cccc}
\hline \hline $\mathrm{T}\left[{ }^{\circ} \mathrm{C}\right]$ & $\mathrm{t}_{f}[\mathrm{hr}]$ & $\mathrm{E}_{T}[\mathrm{~kJ}]$ & $\mathrm{C}_{T}[\mathfrak{f}]$ \\
\hline 440.0 & 2.13 & 154.4 & 30.46 \\
450.0 & 1.45 & 156.0 & 29.88 \\
460.0 & 0.99 & 157.8 & 29.64 \\
465.3 & 0.81 & 159.0 & 29.62 \\
470.0 & 0.68 & 160.0 & 29.64 \\
480.0 & 0.47 & 162.3 & 29.79 \\
490.0 & 0.32 & 164.7 & 30.05 \\
500.0 & 0.23 & 167.2 & 30.39 \\
\hline
\end{tabular}

Therefore there is a possibility that an optimal reaction temperature exists when the monomer price is somewhere in the middle of these two extremes. Table 2 shows an example of such cases where the economic cost attains a minimum value along with the optimal temperature of $465.3^{\circ} \mathrm{C}$.

\section{CONCLUSIONS}

The thermal degradation of PS in batch reactors has been investigated to find optimal temperature profiles minimizing the reaction time and the process energy for a desired conversion. It is assumed the pyrolysis mechanism of PS is composed of two reaction pathways, i.e., random degradation and specific degradation. The former is responsible for shifting the MWD in pyrolysis toward lower molecular weights while the latter for generating the monomer products. The theoretical model has been developed using continuous population balance equations. The transient change of MWD of polymers during the pyrolysis was easily tracked by solving three moment equations. The optimization problem finding optimal temperature profiles in this study is of a nonlinear free-end-time/free-end-point type. Then we made a coordinate transformation introducing the conversion as a new independent variable to convert this independent-variable minimization problem to a dependent-variable minimization problem for which standard solution techniques are readily available.

The results of the optimization study are different depending on the choice of the objective functions: the allowable highest temperature is the most favorable condition for the minimum reaction time, while the intermediate isothermal temperature is optimum for minimum energy consumption. As a new optimization criterion combining the two different ones in the above, i.e., minimum time and minimum energy, a cost function is introduced to judge the economical performance of the pyrolysis process. The methodology of this study is expected to be applicable to most industrial pyrolysis processes providing important information for the optimal design and operation of the reactors.

\section{ACKNOWLEDGMENT}

We are grateful for the financial support to this study given by Korea Science and Engineering Foundation under Grant 960502-07-01-3. 


\section{APPENDIX}

The derivation of the moment equations of Eqs. (11) to (16) from Eqs. (5) and (6) is illustrated here [Wang et al., 1995]. First, a continuous population balance equation for polymers is written as follows :

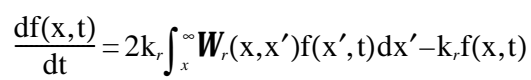

$$
\begin{aligned}
& +\mathrm{k}_{s} \int_{x}^{o} \delta\left[\mathrm{x}-\left(\mathrm{x}^{\prime}-\mathrm{x}_{s}\right)\right] \mathrm{f}\left(\mathrm{x}^{\prime}, \mathrm{t}\right) \mathrm{dx}^{\prime}-\mathrm{k}_{s} \mathrm{f}(\mathrm{x}, \mathrm{t})
\end{aligned}
$$

The function $\Omega_{r}\left(\mathrm{x}, \mathrm{x}^{\prime}\right)$ is a special case of the following general stoichiometric coefficient when $\mathrm{m}$ is set to zero, i.e.,

$$
\Omega_{r}\left(\mathrm{x}, \mathrm{x}^{\prime}\right)=\left[\Omega\left(\mathrm{x}, \mathrm{x}^{\prime}\right)\right]_{m=0}=\left[\mathrm{x}^{m}\left(\mathrm{x}^{\prime}-\mathrm{x}\right)^{m} \frac{\Gamma(2 \mathrm{~m}+2)}{\Gamma(\mathrm{m}+1)^{2}\left(\mathrm{x}^{\prime}\right)^{2 m+1}}\right]_{m=0}=\frac{1}{\mathrm{x}^{\prime}}
$$

where $\Gamma(\mathrm{l})$ is a gamma function which is defined as

$$
\Gamma(\mathrm{N})=\int_{0}^{\infty} \mathrm{e}^{-x} \mathrm{x}^{N-1} \mathrm{dx}
$$

We will here use the general form given by Eq. (A2) in deriving the moment equations and then the conversion will be recovered by substituting $\mathrm{m}=0$ into the resulting equation.

The moment operation is applied to Eq. (A1).

$$
\begin{aligned}
\int_{0}^{\infty} \mathrm{x}^{n} \frac{\mathrm{df}(\mathrm{x}, \mathrm{t})}{\mathrm{dt}} \mathrm{dx}= & 2 \mathrm{k}_{r} \int_{0}^{\infty} \mathrm{x}^{n} \int_{x}^{\infty} \Omega_{r}\left(\mathrm{x}, \mathrm{x}^{\prime}\right) \mathrm{f}\left(\mathrm{x}^{\prime}, \mathrm{t}\right) \mathrm{d \textrm {x } ^ { \prime }} \mathrm{dx}-\mathrm{k}_{r} \int_{0}^{\infty} \mathrm{x}^{n} \mathrm{f}(\mathrm{x}, \mathrm{t}) \mathrm{dx} \\
& +\mathrm{k}_{s} \int_{0}^{\infty} \mathrm{x}^{n} \int_{x}^{\infty} \delta\left[\mathrm{x}-\left(\mathrm{x}^{\prime}-\mathrm{x}_{s}\right)\right] \mathrm{f}\left(\mathrm{x}^{\prime}, \mathrm{t}\right) \mathrm{dx^{ \prime }} \mathrm{dx} \\
& -\mathrm{k}_{s} \int_{0}^{\infty} \mathrm{x}^{n} \mathrm{f}(\mathrm{x}, \mathrm{t}) \mathrm{dx}
\end{aligned}
$$

By interchanging the orders of the integration on both sides of Eq. (A4), we obtain the following equation.

$$
\begin{aligned}
\frac{\mathrm{d}}{\mathrm{dt}}\left[\int_{0}^{\infty} \mathrm{x}^{n} \mathrm{f}(\mathrm{x}, \mathrm{t}) \mathrm{dx}\right]= & 2 \mathrm{k}_{r} \int_{0}^{\infty} \mathrm{f}\left(\mathrm{x}^{\prime}, \mathrm{t}\right) \int_{0}^{x^{\prime}} \mathrm{x}^{n} \Omega_{r}\left(\mathrm{x}, \mathrm{x}^{\prime}\right) \mathrm{dxd \textrm {x } ^ { \prime }} \\
& -\mathrm{k}_{r} \int_{0}^{\infty} \mathrm{x}^{n} \mathrm{f}(\mathrm{x}, \mathrm{t}) \mathrm{dx} \\
& +\mathrm{k}_{s} \int_{0}^{\infty} \mathrm{f}\left(\mathrm{x}^{\prime}, \mathrm{t}\right) \int_{0}^{x^{\prime}} \mathrm{x}^{n} \delta\left[\mathrm{x}-\left(\mathrm{x}^{\prime}-\mathrm{x}_{s}\right)\right] \mathrm{dxdx^{ \prime }} \\
& -\mathrm{k}_{s} \int_{0}^{\infty} \mathrm{X}^{n} \mathrm{f}(\mathrm{x}, \mathrm{t}) \mathrm{dx}
\end{aligned}
$$

Since the second term on the RHS of Eq. (A5) is simply by definition the nth moment of $\mathrm{f}, \mathrm{f}^{(n)}$, here we only show the calculation of the first and the third terms.

$$
\begin{aligned}
& \int_{0}^{\infty} \mathrm{f}\left(\mathrm{x}^{\prime}, \mathrm{t}\right) \int_{0}^{x^{\prime}} \mathrm{x}^{n} \Omega_{r}\left(\mathrm{x}, \mathrm{x}^{\prime}\right) \mathrm{dxd \textrm {x } ^ { \prime }} \\
&=\int_{0}^{\infty} \mathrm{f}\left(\mathrm{x}^{\prime}, \mathrm{t}\right) \int_{0}^{x^{\prime}} \mathrm{x}^{n} \mathrm{x}^{m}\left(\mathrm{x}^{\prime}-\mathrm{x}\right)^{m} \Gamma(2 \mathrm{~m}+2) \\
& \quad /\left.\left[\Gamma(\mathrm{m}+1)^{2}\left(\mathrm{x}^{\prime}\right)^{2 m+1}\right] \mathrm{d} \mathrm{xdx}^{\prime}\right|_{\mathrm{m}=0} \\
&=\int_{0}^{\infty} \mathrm{f}\left(\mathrm{x}^{\prime}, \mathrm{t}\right) \int_{0}^{x^{\prime}} \mathrm{x}^{m+n} \sum_{=0}^{m}(-1)^{m-j}\left(\begin{array}{c}
\mathrm{m} \\
\mathrm{j}
\end{array}\right)\left(\mathrm{x}^{\prime}\right)^{j} \mathrm{x}^{m-j} \Gamma(2 \mathrm{~m}+2) \\
& /\left.\left[\Gamma(\mathrm{m}+1)^{2}\left(\mathrm{x}^{\prime}\right)^{2 m+1}\right] \mathrm{dxdx^{ \prime }}\right|_{m=0} \\
&= \sum_{j=0}^{m}\left[(-1)^{m-j}\left(\begin{array}{c}
\mathrm{m} \\
\mathrm{j}
\end{array}\right) \Gamma(2 \mathrm{~m}+2) / \Gamma(\mathrm{m}+1)^{2} \int_{0}^{\infty}\left(\mathrm{x}^{\prime}\right)^{-2 m+j-1} \mathrm{f}\left(\mathrm{x}^{\prime}, \mathrm{t}\right)\right. \\
&\left.\int_{0}^{x^{\prime}} \mathrm{x}^{2 m+n-j} \mathrm{dxdx} \mathrm{x}^{\prime}\right]_{m=0} \\
&= \sum_{=0}^{m}\left[(-1)^{m-j}\left(\begin{array}{c}
\mathrm{m} \\
\mathrm{i}
\end{array}\right) \Gamma(2 \mathrm{~m}+2) \Gamma(\mathrm{m}+1)^{2} / .(2 \mathrm{~m}+\mathrm{n}-\mathrm{j}+1)\right]
\end{aligned}
$$

$$
\begin{aligned}
= & \sum_{j=0}^{m}\left[(-1)^{m-j}\left(\begin{array}{c}
\mathrm{m} \\
\mathrm{j}
\end{array}\right) \Gamma(2 \mathrm{~m}+2) \Gamma(\mathrm{m}+1)^{2}(2 \mathrm{~m}+\mathrm{n}-\mathrm{j}+1)\right]_{m=0} \\
& \int_{0}^{\infty}\left(\mathrm{x}^{\prime}\right)^{n} \mathrm{f}\left(\mathrm{x}^{\prime}, \mathrm{t}\right) \mathrm{d \textrm {x } ^ { \prime }} \\
= & {[\Gamma(2 \mathrm{~m}+2) \Gamma(\mathrm{m}+\mathrm{n}+1) \Gamma(\mathrm{m}+1) \Gamma(2 \mathrm{~m}+\mathrm{n}+2)]_{m=0} \mathrm{f}^{(n)}(\mathrm{t}) } \\
= & {\left[\mathrm{Z}_{n m}\right]_{m=0} \mathrm{f}^{(n)}(\mathrm{t}) }
\end{aligned}
$$

where $\mathrm{Z}_{n m}=\Gamma(2 \mathrm{~m}+2) \Gamma(\mathrm{m}+\mathrm{n}+1) \Gamma(\mathrm{m}+1) \Gamma(2 \mathrm{~m}+\mathrm{n}+2)$

$$
\begin{aligned}
& \int_{0}^{\infty} \mathrm{f}\left(\mathrm{x}^{\prime}, \mathrm{t}\right) \int_{0}^{x^{\prime}} \mathrm{x}^{n} \delta\left[\mathrm{x}-\left(\mathrm{x}^{\prime}-\mathrm{x}_{s}\right)\right] \mathrm{d} \mathrm{xdx}^{\prime} \\
& \quad=\int_{0}^{\infty}\left(\mathrm{x}^{\prime}-\mathrm{x}_{s}\right)^{n} \mathrm{f}\left(\mathrm{x}^{\prime}, \mathrm{t}\right) \mathrm{d} \mathrm{x}^{\prime} \\
& \quad=\int_{0}^{\infty} \sum_{j=0}^{m}(-1)^{n-j}\left(\begin{array}{l}
\mathrm{n} \\
\mathrm{j}
\end{array}\right)\left(\mathrm{x}^{\prime}\right)^{j} \mathrm{x}_{s}^{n-j} \mathrm{f}\left(\mathrm{x}^{\prime}, \mathrm{t}\right) \mathrm{dx^{ \prime }} \\
& =\sum_{=0}^{m}\left[(-1)^{n-j}\left(\begin{array}{l}
\mathrm{n} \\
\mathrm{j}
\end{array}\right) \mathrm{x}_{s}^{n-j} \int_{0}^{\infty}\left(\mathrm{x}^{\prime}\right)^{j} \mathrm{f}\left(\mathrm{x}^{\prime}, \mathrm{t}\right) \mathrm{dx^{ \prime }}\right] \\
& =\sum_{j=0}^{n}\left[\mathrm{~W}_{n j} \mathrm{f}^{(j)}(\mathrm{t})\right]
\end{aligned}
$$

where $\mathrm{W}_{n j}=(-1)^{n-j}\left(\begin{array}{l}\mathrm{n} \\ \mathrm{j}\end{array}\right) \mathrm{x}_{s}^{n-j}$

The resulting moment equation for the polymer is now

$$
\begin{aligned}
\frac{\mathrm{df}^{(n)}(\mathrm{t})}{\mathrm{dt}} & =2 \mathrm{k}_{r} \mathrm{Z}_{n 0} \mathrm{f}^{(n)}(\mathrm{t})-\mathrm{k}_{r} \mathrm{f}^{(n)}(\mathrm{t})+\mathrm{k}_{s} \sum_{=0}^{n}\left[\mathrm{~W}_{n j} \mathrm{f}^{(j)}(\mathrm{t})\right]-\mathrm{k}_{s} \mathrm{f}^{(n)}(\mathrm{t}) \\
& =\left[2 \mathrm{k}_{r} \mathrm{Z}_{n 0}-\mathrm{k}_{r}-\mathrm{k}_{s}\right] \mathrm{f}^{(n)}(\mathrm{t})+\mathrm{k}_{s} \sum_{s=0}^{n}\left[\mathrm{~W}_{n j} \mathrm{f}^{(j)}(\mathrm{t})\right]
\end{aligned}
$$

where $Z_{00}=1, Z_{10}=1 / 2, Z_{20}=1 / 3$

$$
\mathrm{W}_{00}=1, \mathrm{~W}_{10}=-\mathrm{X}_{s}, \mathrm{~W}_{11}=1, \mathrm{~W}_{20}=-\mathrm{X}_{s}^{2}, \mathrm{~W}_{21}=-2 \mathrm{x}_{s}, \mathrm{~W}_{22}=1
$$

Finall, the above equation produces the following equations for the MWD of polymers when $n$ takes on the values of 0,1 and 2 .

$$
\begin{aligned}
\frac{\mathrm{df}^{(0)}(\mathrm{t})}{\mathrm{dt}} & =\left[2 \mathrm{k}_{r} \mathrm{Z}_{00}-\mathrm{k}_{r}-\mathrm{k}_{s}\right] \mathrm{f}^{(0)}(\mathrm{t})+\mathrm{k}_{s} \mathrm{~W}_{00} \mathrm{f}^{(0)}(\mathrm{t}) \\
& =\mathrm{k}_{r} \mathrm{f}^{(0)}(\mathrm{t}) \\
\frac{\mathrm{d \textrm {f } ^ { ( 1 ) }}(\mathrm{t})}{\mathrm{dt}} & =\left[2 \mathrm{k}_{r} \mathrm{Z}_{10}-\mathrm{k}_{r}-\mathrm{k}_{s}\right] \mathrm{f}^{(1)}(\mathrm{t})+\mathrm{k}_{s} \sum_{j=0}^{\mathrm{t}} \mathrm{W}_{1 j} \mathrm{f}^{(j)}(\mathrm{t}) \\
& =-\mathrm{k}_{s} \mathrm{f}^{(1)}(\mathrm{t})+\mathrm{k}_{s}\left[-\mathrm{x}_{s} \mathrm{f}^{(0)}(\mathrm{t})+\mathrm{f}^{(1)}(\mathrm{t})\right] \mathrm{f}^{(1)}(\mathrm{t}) \\
& =-\mathrm{k}_{s} \mathrm{x}_{s} \mathrm{f}^{(0)}(\mathrm{t}) \\
\frac{\mathrm{df} \mathrm{f}^{(2)}(\mathrm{t})}{\mathrm{dt}} & =\left[2 \mathrm{k}_{r} \mathrm{Z}_{20}-\mathrm{k}_{r}-\mathrm{k}_{s}\right] \mathrm{f}^{(2)}(\mathrm{t})+\mathrm{k}_{s} \sum_{j=0}^{2} \mathrm{~W}_{2 j} \mathrm{f}^{(j)}(\mathrm{t}) \\
& =\left[-(1 / 3) \mathrm{k}_{r}-\mathrm{k}_{s}\right] \mathrm{f}^{(2)}(\mathrm{t})+\mathrm{k}_{s}\left[\mathrm{x}_{s}^{2} \mathrm{f}^{(0)}-2 \mathrm{x}_{s} \mathrm{f}^{(1)}(\mathrm{t})+\mathrm{f}^{(2)}(\mathrm{t})\right] \\
& =-(1 / 3) \mathrm{k}_{r} \mathrm{f}^{(2)}(\mathrm{t})-2 \mathrm{k}_{s} \mathrm{x}_{s} \mathrm{f}^{(1)}(\mathrm{t})+\mathrm{k}_{s} \mathrm{x}_{s}^{2} \mathrm{f}^{(0)}(\mathrm{t})
\end{aligned}
$$

For the MWD of monomers, a similar procedure is followed to obtain the following moment equations.

$$
\frac{\mathrm{dg}^{(n)}(\mathrm{t})}{\mathrm{dt}}=\mathrm{k}_{s} \mathrm{X}_{s}^{n} \mathrm{f}^{(0)}(\mathrm{t})
$$

When $\mathrm{n}=0,1$ and 2, 


$$
\begin{aligned}
& \frac{\mathrm{dg}^{(0)}(\mathrm{t})}{\mathrm{dt}}=\mathrm{k}_{s} \mathrm{f}^{(0)}(\mathrm{t}) \\
& \frac{\mathrm{dg}^{(1)}(\mathrm{t})}{\mathrm{dt}}=\mathrm{k}_{s} \mathrm{X}_{s} \mathrm{f}^{(0)}(\mathrm{t}) \\
& \frac{\mathrm{dg}^{(2)}(\mathrm{t})}{\mathrm{dt}}=\mathrm{k}_{s} \mathrm{X}_{s}^{2} \mathrm{f}^{(0)}(\mathrm{t})
\end{aligned}
$$

\section{NOMENCLATURE}

A : area of reactor wall $\left[\mathrm{m}^{2}\right]$

$\mathrm{c}_{p} \quad$ : heat capacity of reaction mass $\left[\mathrm{kJ} / \mathrm{mol}^{\circ} \mathrm{C}\right]$

$\mathrm{c}_{s} \quad$ : concentration of monomers $[\mathrm{g} / \mathrm{L}]$

$\mathrm{C}_{E} \quad$ : electricity cost $[\mathbf{f}]$

$\mathrm{C}_{M} \quad$ : unrealized monomer cost $[£]$

$\mathrm{C}_{T} \quad$ : total cost for producing $1 \mathrm{~kg}$ of styrene monomer [£]

$\mathrm{E}_{T} \quad$ : total energy consumed for obtaining $90 \%$ conversion [kJ]

$\mathrm{E}_{T}^{*} \quad$ : total energy consumed for producing $1 \mathrm{~kg}$ of styrene monomer $[\mathrm{kJ} / \mathrm{kg}]$

$\mathrm{E}_{r} \quad$ : activation energy of the random degradation reaction [kcal $/ \mathrm{mol}]$

$\mathrm{E}_{s} \quad$ : activation energy of the specific degradation reaction [kcal/ mol]

$\mathrm{f}^{(n)} \quad$ : nth order molecular weight moment of $\mathrm{f}$ defined as Eq. (17)

$f(x, t)$ : molecular weight distribution of the polymers based on molar fraction $[\mathrm{mol} / \mathrm{L}]$

$\mathrm{f}_{w}(\mathrm{x}, \mathrm{t})$ : molecular weight distribution of the polymers based on weight fraction $[\mathrm{g} / \mathrm{L}]$

F : state equations given by Eqs. (11) to (16)

$\mathrm{g}^{(n)} \quad$ : nth order molecular weight moment of $\mathrm{g}$ defined as Eq. (18)

$g(x, t)$ : molecular weight distribution of the monomers based on molar fraction [mol/L]

$\mathrm{g}_{w}(\mathrm{x}, \mathrm{t})$ : molecular weight distribution of the monomers based on weight fraction $[\mathrm{g} / \mathrm{L}]$

$\mathrm{G} \quad$ : transformed state equations given by Eqs. (31) and (32)

$\Delta \mathrm{H}_{d}$ : heat of depolymerization of polystyrene [ $[\mathrm{kJ} / \mathrm{mol}]$

$\mathrm{k}_{r} \quad$ : reaction rate constant of the random degradation reaction $\left[\mathrm{hr}^{-1}\right]$

$\mathrm{k}_{r 0} \quad$ : frequency factor of the random degradation reaction $\left[\mathrm{hr}^{-1}\right]$

$\mathrm{k}_{s} \quad$ : reaction rate constant of the specific degradation reaction $\left[\mathrm{hr}^{-1}\right]$

$\mathrm{k}_{\mathrm{s} 0} \quad$ : frequency factor of the specific degradation reaction $\left[\mathrm{hr}^{-1}\right]$

$\mathrm{m}$ : weight of reaction mixtures $[\mathrm{kg}]$

$\overline{\mathbf{M}}_{n} \quad$ : number average molecular weight $[\mathrm{g} / \mathrm{mol}]$

$\dot{\mathrm{q}}_{c} \quad$ : cooling rate by heat transfer with atmosphere $[\mathrm{kJ} / \mathrm{hr}]$

$\dot{\mathrm{q}}_{h} \quad$ : heating rate by heat source $[\mathrm{kJ} / \mathrm{hr}]$

$\mathrm{r}_{d} \quad$ : rate of pyrolysis reaction $[\mathrm{mol} / \mathrm{L} \mathrm{hr}]$

$\mathrm{R}$ : universal gas constant $[\mathrm{kcal} / \mathrm{mol} \mathrm{K}]$

$\mathrm{t} \quad$ : reaction time $[\mathrm{hr}]$

$\mathrm{t}_{f} \quad$ : final reaction time taken for obtaining $90 \%$ conversion [hr]

$\mathrm{t}_{f}^{*} \quad:$ the shortest realized reaction time in Table $1[\mathrm{hr}]$

$\mathrm{T}$ : reaction temperature $\left[{ }^{\circ} \mathrm{C}\right]$

$\mathrm{T}_{a} \quad$ : room temperature $\left[{ }^{\circ} \mathrm{C}\right]$
$\mathrm{U}$ : overall heat transfer coefficient $\left[\mathrm{W} / \mathrm{m}^{\circ} \mathrm{C}\right]$

$\mathrm{V}$ : reactor volume $\left[\mathrm{m}^{3}\right]$

$\mathrm{x} \quad$ : molecular weight of polymers $[\mathrm{g}]$

$\mathrm{x}_{0} \quad$ : lowest molecular weight in polymer samples [g]

$\mathrm{X}_{s} \quad$ : molecular weight of monomers [g]

y : transformed variables given by Eqs. (27) to (30)

\section{Greek Letters}

$\alpha \quad$ : parameter in the gamma distribution

$\beta \quad$ : width parameter in the gamma distribution

$\delta \quad$ : Dirac delta function

$\Gamma \quad$ : gamma function

$\rho \quad:$ density of reaction mixtures $[\mathrm{kg} / \mathrm{L}]$

$\sigma^{2}$ : variance of the molecular weight distribution

$\tau \quad$ : new time variable denoting the conversion of the pyrolysis reaction $[\mathrm{hr}]$

$\tau_{f} \quad$ : final time denoting the final conversion [hr]

$\Omega_{r} \quad$ : stoichiometric coefficient for the random degradation given by Eq. (7)

$\Omega_{s} \quad$ : stoichiometric coefficient for the specific degradation given by Eqs. (8) and (9)

\section{REFERENCES}

Flynn, J. H. and Florin, R. E., "Degradation and Pyrolysis Mechanisms," Pyrolysis and GC in Polymer Analysis, Liebman, S. A. and Levy, E. J., Eds., Marcel Dekker, Inc., New York (1985).

Kaminsky, W., "Pyrolysis of Polymers,' Emerging Technologies in Plastics Recycling, Andrews, G. D. and Subramanian, P. M., Eds., American Chemical Society, Philadelphia, 60 (1992).

Kirk, D. E., “Optimal Control Theory : An Introduction,' PrenticeHall, London (1970).

Kwon, Y. D. and Evans, L. B., "A Coordinate-Transformation Method for the Numerical Solution of Nonlinear Minimum-Time Control Problems," AIChE J., 21, 1158 (1975).

Madras, G. and McCoy, B. J., "Time Evolution of Similarity Solutions for Polymer Degradation,' AIChE J., 44(3), 647 (1998).

Madras, G., Chung, G. Y., Smith, J. M. and McCoy, B. J., "Molecular Weight Effect on the Dynamics of Polystyrene Degradation,' Ind. Eng. Chem. Res., 36(6), 2019 (1997a).

Madras, G., Smith, J. M. and McCoy, B. J., "Thermal Degradation Kinetics of Polystyrene in Solution,' Polym. Degrad. Stab., 58, 131 (1997b).

McCoy, B. J. and Madras, G., "Degradation Kinetics of Polymers in Solution : Dynamics of Molecular Weight Distributions," AIChE J., 43(3), 802 (1997).

Odian, G., "Principles of Polymerization," $3^{\text {rd }}$ ed., Wiley-Interscience, New York (1991).

Rao, S. S., "Engineering Optimization : Theory and Practice," John Wiley \& Sons, Inc., New York (1996).

Reklaitis, G. V., Ravindran, A. and Ragsdell, K. M., "Engineering Optimization : Methods and Applications," Wiley-Interscience, New York (1983).

Sato, S., Murakata, T., Baba, S., Saito, Y. and Watanabe, S., "Solvent Effect on Thermal Degradation of Polystyrene,' J. Appl. Polym. Sci., 40, 2065 (1990).

Song, H.-S., Park, Y. D. and Hyun, J. C., "Optimization for the 
Minimum Reaction Time of PET Esterification,' Korean J. Chem. Eng., 13, 369 (1996).

Van Krevelen, D. W., "Properties of Polymers," $3^{\text {rd }}$ ed., Elsevier, New York (1990).

Wang, M., Smith, J. M. and McCoy, B. J., "Continuous Kinetics for Thermal Degradation Polymer in Solution,' AIChE J., 41
(6), 1521 (1995).

Westerhout, R. W. J., Waanders, J., Kuipers, J. A. M. and van Swaaij, W.P.M., "Kinetics of the Low-Temperature Pyrolysis of Polyethene, Polypropene, and Polystyrene Modeling, Experimental Determination, and Comparison with Literature Models and Data,' Ind. Eng. Chem. Res., 36(6), 1955 (1997). 